The two dynamos act as generators and furnish $V$. This soon energy is expended upon the resistance, speed is still further reduced by diminishing the re sistance of $V$ and thus increasing the work of the sistance of $V$ and thus increasing the work of the
lynamo. When the resistance is reduced to 0 , so that the two dynamos are connected directly together in the two dynamos are connected directly together in
short circuit, the braking action is strongest, as shown in position 7 .

The reverse is obtained by position 8. Afte the braking action has been secured by position 7 , a shunt of high resistance is connected to the field $M$, of dynamo 1. This is the reverse of position and in this case the opposing electromotive force gen
erated in dynamo 2 is reduced so that the acmature of the latter now runs in the opposite direction, and the rear shaft, $B$, is thus turned in the opposite direction to the motor shaft, $C$. The chauffeur can thus drive the car by simply operating the controller handle and can run from a very slow up to a high speed, ap-
ply the electric brake, or reverse the car. The con troller can be built so as to give any desired number of inta-mediate positions by using variable resistances, so that the speed changing is operated very smoothly and without shocks.

The Electrogenia car uses a method of electric transmission which is designed on an entirely different principle from the former. Our illustration shows a chassis on which can be seen the different parts. The gasoline motor is at the front of the chassis, as usual. It drives a dynamo, which is mounted directly in line with its crankshaft. The dynamo sends current into an electric motor, which drives the differential on the rear axle. By varying the current by a controller, any number of different speeds can be given to the rear wheels, while the gasoline motor runs at a constant speed. This system has been

The gasoline motor is of the Aster pattern and gives 12 horse-power. The dynamo is of the shuntwound type, while the motor is series-wound. It has wound type, while the motor is series-wound. It has
two circuits for the field and two for the armature. two circuits for the field and two for the armature.
The circuits of dynamo and motor are all brought to the controller, which the chauffeur operates by a handthe controller, which the chauffeur operates by a hand-
wheel. Four positions are used to give the different wheel. Four positions are used to give the different
speeds to the car. These four methods of coupling corspeeds to the car. These four methods of coupling cor-
respond to four different speeds of the car, while the gasoline motor continues to drive the generator at a gasoline motor continues to drive the generator at a duced on this system by using auxiliary resistances to auced on this system by using auxiliary resistances to when the gasoline motor is slowed down, it reduces the voltage of the generator accordingly, and the car can thus be slowed down to a full stop by a variation in the gasoline motor alone, without having to break the current or otherwise operate the controller. In the
same way the car can be started from rest by starting the gasoline motor.

It is claimed that the present electric system of transmission has a much higher efficiency than the mechanical system. Some authorities state that the gear transmission which is in general use on automobiles gives a loss of 50 per cent of the power of the motor. At any rate, the loss is considerable. A series of tests were made upon the Electrogenia car to establish the efficiency of the electric system and compare it with the above. This could be easily done by making the electrical measurements. The gasoline motor, when tested by a Prony brake, gave an average of 11.05 horse-power. The generating dynamo furnished 72 amperes and 95 volts, or 6,840 watts. As the power of the motor is $8,132.8$ watts, the efficiency of the dynamo figures 85.78 per cent. A current was sent from the generator to the motor, while a Prony brake was placed on the rear axle. The motor was found to utilize 80.2 per cent of the energy furnished it by the dynamo. The total efficiency of the system is thus $85.78 \times 80.2$, or 68.8 per cent. Comparing this result with the 50 per cent cited above (and this is no doubt very often
less) we have a gain of nearly 20 per cent of the total less) we have a gain of nearly 20 per cent of the total
power, or nearly 40 per cent of the power which the power, or nearly 40 per cent of the power which the
car actually uses. Otherwise stated, with the same car actually uses. Otherwise stated, with the same
gasoline motor but using the electric system, we have gasoline motor but using the electric system, we have
more than one-third additional power to be used in running the car. \section{ON THE PERIODIC ARRANGEMENT OF THE
ELEMENTS.*}

By Sir William RaMsay, K.C.B., F.R.S

Ar the end of the eighteenth century, after the investigations of Black, Scheele, Priestley, Cavendish, and Lavoisier began to crystallize the previous arbitrary collections of chemical facts into more or less of a system, it became evident that the distinguishing feature of a "compound," as contrasted with a "mixture," was the invariability of its composition. Early in the nineteenth century, Dalton formulated his celebrated liypothesis, by means of which a concrete view was the cause of this constancy and invariability of composition. Everyone knows that this "explanation" consisted in the supposition that the combination of two substances, one with another, in refinite proportions, involves the union either of one atom of the one with one atom of the other, or of certain small but simple numbers of atoms of the two
substances. The atom was regarded, not necessarily substances. The atom was regarded, not necessarily
as indivisible, but as not having been divided into any as indivisible, but as not having been divided into any smaller particles. The advance made by Dalton consisted chiefly in ascribing to each atom a definite
weight; but as he had no data for determining the absolute weight of any one atom, he was obliged to himself with relative weights, and chose the smallest known to him, that of hydrogen, as an arbi trary unit. This choice has proved to be a just one for as yet no element has been discovered possessing a
lower atomic weight than hydrogen, although it is by no means impossible that such an element may exist. After the convenience of Dalton's hypothesis had been acknowledged, the labor of chemists was for many years devoted to the determination of the relative values of the "atomic weights" of the elements; or expressed in a manner independent of hypothesis, of their comberzelius, is prominent in this connection. By the analysis of an almost incredibly large number of compounds, he established on a firm basis the constancy
of composition of compounds, and the law of multiple of composition of compounds, and the law of multiple
proportions. Toward the ' 40 's, therefore, a set of numbers had been collected, which invited an attempt to place them in order, with the view of seeing whether some still more profound law could not be discovered connecting the combining numbers attached to them. Döbereiner, as early as 1817 , and again in 1829 , pointed out that certain elements had atomic weights which were nearly the mean of those of others which were closely related to them; thus, the mean of the atomic weights of calcium and barium gives a close approximation to the atomic weight of strontium; that of sodium lies near the mean of those of lithium and potassium; and sulphur and tellurium similarly indicate selenium as a middle element. In 1843, Gmelin, who published a-"Handbook of Chemistry" which is still a classic, attempted a classification based, not upon numerical relations, but on similarity of properties. For instance, we find the groups- $-\mathrm{F}, \mathrm{Cl}, \mathrm{Br}, \mathrm{I} ; \mathrm{S}, \mathrm{Se}, \mathrm{Te}$; $\mathrm{P}, \mathrm{As}, \mathrm{Sb} ; \mathrm{C}, \mathrm{B}, \mathrm{Si} ; \mathrm{Li}, \mathrm{Na}, \mathrm{K} ; \mathrm{Mg}$, Ca, Sr, Ba; and so Association, in which he showed that not merely is the atomic weight of bromine the mean of those of chlorine and iodine, but that its physical properties, such as its color, its density in the gaseous and in the liquid state, color, its density in the gaseous and in the liquid state,
etc., are also half-way between those of the allied elements. In 1852, Faraday criticised Dumas's attempts as "speculations which have scarcely yet assumed the consistence of a theory, and which are only at the
present time to be ranked among the poetic day-dreams present time to be ranked among the poetic day-dreams to have the dawning of a new light indicative of the to have the dawning of a new light indicative of the
mutual convertibility of certain groups of elements, although under conditions which are as yet hidden from our scrutiny."

Passing over attempts by Gladstone, Cooke, Odling, and Strecker, we come to the years 1863 and 1864 , when John Newlands, in a series of letters to the
Chemical News, announced what he termed the "Law of Octaves." His actual words were: "If the elements are arranged in the order of their equivalents, with a few slight transpositions, it will be observed pear on the same horizontal line. It will also be seen that the numbers of analogous elements generally
differ, either by 7 or by some multiple of 7 ; in other differ, either by 7 or by some multiple of 7 ; in other
words, members of the same group stand to each other words, members of the same group stand to each other in the same relation as the extremities of one or more octaves in music. Thus, in the nitrogen group, between nitrogen and phosphorus there are 7 elements between phosphorus and arsenic, 14; between arsenic bismuth, 14 also. provisionally to term the 'Law of Octaves.'

In 1869 and 1870, Lothar Meyer and Dmitri Menrleléeff, independently of Newlands, and also of each other, published papers in which they maintained that the properties of the elements are periodic functions of their atomic weights. This discovery goes by the nam of the "Periodic Law," or better, the "Periodic Sysfers but little from that of Mendeléeff, is the one gen erally adopted.

If this diagram is rolled round a cylinder, it will If this diagram is rolled round a cylinder, it will
form a continuous spiral, beginning with lithium and form a continuous spiral, beginning with lithium and
ending with uranium; but there are certain gaps un filled, denoted by the sign ?, which, it is believed, repre sent the places of still undiscovered elements. Indeed, Meyer's original diagram contained a larger number of these; and Mendeléeff, averaging the properties of the elements surrounding such gaps, prophesied th discovery of scandium, gallium and germanium, made at a much later date and by Winckler.

There are many other ways of representing these re lations; but, except perhaps in convenience (and ques-
tionably even in that), they present no particular adtionably even in that), they present no particular advantage, and convey no new knowledge. Only one point must be emphasized. The elements, as arranged above, divide themselves into two "periods"-long periods and short periods. Thus, the seventh member after lithium, sodium, is in its character very like lithium; and again, potassium, the seventh after sodium, presents strong analogies with the two elements named before rubidium is reached, which again closely re before rubidium is reached, which again closely re
sembles lithium, sodium, and potassium; and cæsium, the fourteenth element after rubidium, forms the first the fourteenth element after rubidium, forms the first
term of another long period. Copper, silver, and gold term of another long period. Copper, silver, and gold
are also separated by long periods; and so with the are also separated by long periods; and so with the the table, the symbols of the elements in the middle of the long periods are printed toward the left, and those at the beginning toward the right, of the figures denoting the atomic weight

One other point requires mention. Several instances occur, in which the elements appear to occupy a re- versed position. Thus, nickel, with the atomic weight 58.7, follows cobalt, to which a higher atomic weigh iodine; and it will be seen that argon precedes potassium. The differences between the various consecutive atomic weights are irregular, and vary between fairly wide limits; and it is quite probable that these differences may occasionally be negative.

In 1894, a new constituent of the atmosphere, which was named "argon," was discovered by Lord Rayleigl and Ramsay; this was followed, in 1895, by the discovery by Ramsay of helium in certain minerals. This
gas gives a spectrum in which a brilliant yellow line

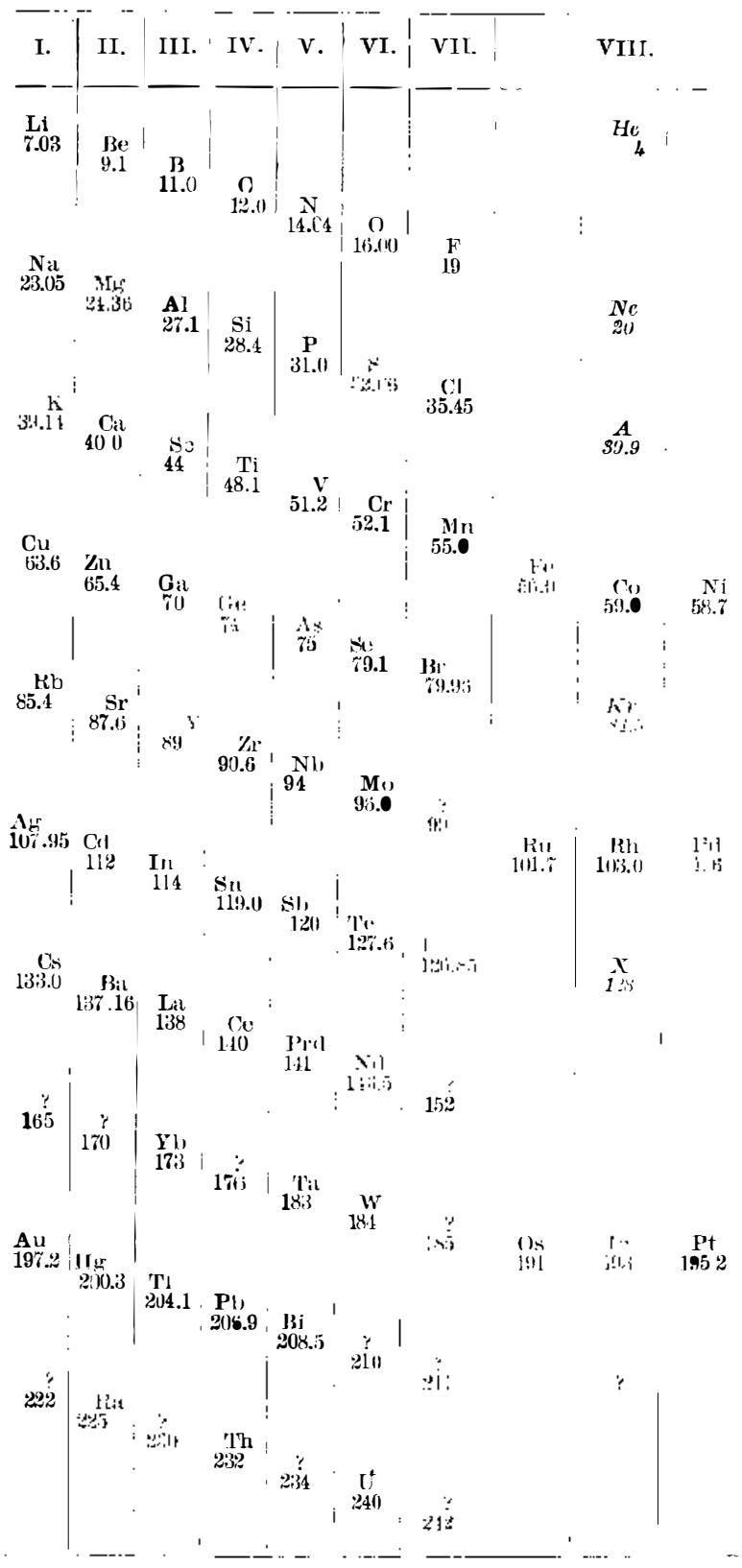

is conspicuous. So long ago as 1868 this line haul been observed in the solar spectrum by Jansen; it was attributed to the presence of a new element in the then unknown element "helium." These discoveries were followed by that of three other gaseous elements in atmospheric air, by Ramsay and Travers in 1898. thus five elements were added to the list. All these elements are distinguished by their inertness, for none of ments are distinguished by their inertness, for
them forms compounds with other elements.

The Roman figures at the head of the columns of the The Roman figures at the head of the columns of the
periodic table have a certain significance. They show periodic table have a certain significance. They show
the maximum number of atoms of hydrogen which the elements in each column can combine with or replace, or, as it is termed, their "valency." Thus, an atom of lithium combines with one atom of hydrogen; it can also replace one atom, as when it forms roxide, $\mathrm{LiOH}$, in which it has replaced one atom of hydrogen in water, $\mathrm{H}_{2} \mathrm{O}$. So also, magnesium can replace two atoms of hydrogen, for it forms the hydroxide
$\mathrm{Mg}(\mathrm{OH})$. Boron combines with three atoms of hy$\mathrm{Mg}(\mathrm{OH})_{2}$. Boron combines with three atoms of hy-
drogen, carbon with four; phosphorus, although it can combine with only three atoms of hydrogen, can replace five; for it forms a chloride $\mathrm{PCl}_{5}$, in which it has replaced the five atoms of hydrogen in five molecules of hydrogen chloride, $5 \mathrm{HCl}$. Sulphur forms a hexafluoride, and iodine a heptafluorirle, in which they replace six and seven atoms of hydrogen respectively, in $6 \mathrm{HF}$, and in $7 \mathrm{HF}$. Only one of the elements of the eighth group appears to be able to replace 8 atoms of hydrogen. amely, osmium; it forms a tetroxide, $\mathrm{Os} \mathrm{O}_{k}$, thus $\mathrm{re}$. lacing the eight atoms of hydrogen in four molecules water, $4 \mathrm{H}_{3} \mathrm{O}$. But the new gaseous elements of the as the power of replacing or combining with hydrogen is termed. They thus form a column by themselves; and it was interesting to ascertain whether their atomic weiĝ́hts would form a series like those in the other columns. In this case, the atomic weight the other columns. In this case, the atomic weight mining the ratio in which the elements combine with mining the ratio in which the elements combine with
hydrogen; hence a different method was adopted, dehydrogen; hence a different method was adopted, de-
pending on the known fact that erual numbers of mole-
cules of gases occupy equal volumes under the same conditions of temperature and pressure; and making 
use of an argument relating to the number of atoms in
such molecules. The atomic weights were: such molecules. The atomic weights wer
Hlelium Neon Argon

$\begin{array}{ccccc}\text { Thelium } & \text { Neon } & \text { Argon } & \text { Krypton } & \text { Xenon } \\ 4 & 20 & 39.9 & 81.5 & 128\end{array}$

These numbers, as will be seen on reference to the

table, fit in the eighth column; the symbols and atomic weights of these gases are printed in italics. They form the initial members of the first, second, and thir short series, and of the first and second long series.

Some doubt exists as to the place to be assigned to
hydrogen, the element with lowest atomic weight. Both Mendeléeff and Meyer shirked placing it. It may be that it should be placed at the head of the fluorine column; but there are equally good, or perhaps better
reasons for believing that it is the first member of the reasons for believin

Many attempts have been made to devise some mathe matical relation betwocn these atomic weights. So long as there was reason to doubt the accuracy of the experiments by means of which the atomic weights have been determined, some such relation as the followthe differences between the ato in its favor: Taking ments in the first column, lithium, sodium, potassium, rubidium, and cæsium, they are

$\mathrm{Na}-\mathrm{Li}=23-7=16$
$\mathrm{~K}-\mathrm{Na}=39-23=16$
$\mathrm{Rb}-\mathrm{K}=85-39=46=$

$\mathrm{Rb}-\mathrm{K}=85-39=46=(3 \times 16)$ nearly

$\mathrm{Cs}-\mathrm{Rb}=133-85=48=(3 \times 16)$.

The differences are $16,16,3 \times 16$, and $3 \times 16$. Now there are compounds of carbon and hydrogen, which possess the formulæ, $\mathrm{CH}_{4}, \mathrm{C}_{3} \mathrm{H}_{6}, \mathrm{C}_{3} \mathrm{H}_{8}, \mathrm{C}_{4} \mathrm{H}_{10}, \mathrm{C}_{5} \mathrm{H}_{1: 3}, \mathrm{C}_{6} \mathrm{H}_{1,}$ etc.; and as the atomic weight of carbon is 12 , and that
of hydrogen 1, the sum of the atomic weights, or, as they are called, the molecular weights, are respectively $16,30,44,58,72,86$, etc., with a common difference of 1.4. IVe see therefore, that a set of compounds may so differ in molecular weight as to present a regular series, with a common difference. Nothing was more likely,
then, than that solium should be regarded as a comthen, than that solium should be regarded as a com-
pound of one atom of lithium with one atom of an unknown element of atomic weight 16 , or with two atoms of an unknown element of atomic weight 8 ; while potassium might be looked upon as a compound of an atom of lithium, with four atoms of the element of atomic weight 8 ; and so on. But, unfortunately for this simple theory, the differences between the atomic weights of the elements are not exactly equal. Instead of 16 , the real difference between the atomic weights of lithium and sodium is 16.02 ; between potassium and sodium, 16.09, and so on.

the divergences are still more striking.

The cause of this irregularity has, therefore, to be Are the atomic weights invariable? A further question is: Is weight invariable? Does a body always possess the same weight under all conditions? For example, would the weight of a body remain the same, if it were to be weighed at different temperatures? Or, if elec
trically charged, would its weight remain unaltered. It is a very difficult problem to weigh an object at a
trically charged, would its weight remain unaltered It is a very difficult problem to weigh an object at a
high temperature. If the balance, as is usual, contains high temperature. If the balance, as is usual, contains
air, convection currents are produced by the ascent of air, convection currents are produced by the ascent of
air heated by the warm body, and the body apparently welghs too little. If the whole balance were uniformly heated, the weights would be at the same temperature as the substance weighed; and it is to be presumed that both they and the substance would alter in weight
equally, and still remain in counterpoise. And if the equally, and still remain in counterpoise. And if the Crookes in determining the atomic weight of thallium, other phenomena intervene, which, however interesting other phenomena intervene, which, however interesting
in themselves (they led Crookes to the invention of in themselves (they led Crookes to the invention of
the radiometer), are very disconcerting; for attractions and repulsions, which completely disturb equilibrium, are produced by the slightest variations of temperature. However, some curious calculations have been made by Hicks in dealing with Baily's experiments on the attraction of leaden balls by masses of lead-experiments which afford data for calculating the density of the earth. At a high temperature the attraction appeared to be less than at a low one; and as the attraction of veriments to be correct, and the deductions legitimate, it would follow that weight is altered by temperatur The subject is well worthy of further experiment. Again, interesting experiments have been made by Landolt, as regards constancy of weight. Having sealeit up in an inverted U-tube, two substances capable
of acting on each other, such as silver nitrate and sodium chloride, each substance in solution occupying one limb of the tube, he weighed the tube with the one limb of the tube, he weighed the tube with the
utmost accuracy; the possible error might be one part utmost accuracy; the possible error might be one part
in a million. On inverting the tube, the two solutions
mixed, and the reaction took place. It was again mixed, and the reaction took place. It was again
weighea. For long, Landolt supposed that he had detected small changes in weight, sometimes negative, sometimes positive; but he was able to trace these
changes to the porous nature of glass. On employing tubes made of fused quartz, no change of weight could be detected after the reaction was over. Apparently, therefore, no change of weight takes place as the result of a chemical reaction, provided nothing leaves
enters the vessel in which the reaction goes on.

A very ingenious experiment of Joly's deserves mention. It was designed to try whether any change of mass occurs on mixing two reacting bodies, and the devised by Lanlolt. But instead of utilizing the attraccion of the ion of the earth in orrler to estimate whether the mass of their mixture was determined. The vessel contain- ing the substances to be mixed was suspended to the
arm of a torsion-lalance, the arm of which was at arm of a torsion-lualance, the arm of which was at which is known to be at the rate of about 30 miles a econd through space. If matter had been created uring the chemical change, then the created matte would not partake of the earth's velocity, and a retarda-
tion, made manifest by the rotation of the arms of the tion, made manifest by the rotation of the arms of the torsion-balance in one direction, would have been ob-
served; and if, on the other hand, matter had been deserved; and if, on the other hand, matter had been de
stroyed, an acceleration would have shown itself. The experiments were entirely negative; hence it may bo concluded, confirmatory of the experiments of Landolt, that no change in mass is produced by a chemical re-
action. A variation in weight or in inertia has not action. A variati

There is one curious discrepancy which still remain unexplained. The density of nitrogen gas has been very accurately determined by two very competen in their - Lord Rayleigh and Leduc. They both agree known, for reasons into which we cannot enter here that the molecules of both nitrogen and oxygen consis each of two atoms; and as it is also certain that equa volumes of gases contain nearly equal numbers of molecules, when measured under similar conditions of temperature and pressure, the relative weights of thes temperature and pressure, the relative weights of thes
gases correspond to the relative weiglits of the atoms. gases correspond to the relative weights of the atoms
The word "nearly" has been used; for a slight cor The word "nearly" has been used; for a slight cor
rection "must be introduced in order to secure exact rection 'must be introduced in order to secure exact
correspondence:- Hence the atomic weight of nitrogen, correspondence. Hence the atomic weight of nitrogen
referred to that of oxygen taken as 16 , as is now cus tomary, must be 14.002 , since that is the density of $n$ trogen referred to oxygen as 16 , after the necessary
correction has been made. But this number does no correction has been made. But this number does no correspond with the atomic weight of nitrogen obtained
by the celebrated chemist Stas, as the result of the an alysis of such compounds as petassium nitrate, when he determined the ratio between the quantities of $\mathrm{ni}$
trogen and oxygen in the molecule $\mathrm{K} \mathrm{N} \mathrm{O}_{3}$. Both he and, quite recently, one of the most skillful of analysts, to whom we owe in recent years many exact determina tions of atomic weights, Theodore Richards, agree in ascribing the number 14.04 to nitrogen as its atomic weight. The difference does not aprear very great; but yet it amounts to one part in 370 : and the error o 10,000 . This discrepancy is one of the most curious of chemical facts, and it would well repay further invest gation. It may be added that the determination by Gray of the density of nitric oxide, a compound con taining one atom of nitrogen in combination with one atom of oxygen, entirely corroborates the results of progress to combine a weighed quantity of nitric oxide with oxygen, so as to cause it to take up one other with oxygen, so as to cause it to take up one other and also to remove from it the atom of oxygen, and to find the weight of the oxygen removed; we may, there fore, hope for some explanation of the above discrepfore, hope for some explanat at no distant date.

The writer of this article was so much impresse by the consideration of this discrepancy, that some
years ago, in conjunction with Miss Aston, an attempt was made to find whether the fact of a compound hav ing been formed with absorption, instead of, as is ner, with evolution of heat, had any influence on the proportions of the elements which it contained
For this purpose the salts of a curious acid derivative of nitrogen named hydrazoic acid, $\mathrm{HN}_{i}$, were analyzed but there is reason to distrust the results, for it is pos
sible that decomposition occurred during the prepara tion to some small extent, and so may not have led
to trustworthy conclusions. But such as they were, to trustworthy conclusions. But such as they were, they were in favor of the supposition that the atomic weight of nitrogen in such compounds is less than in
those formed with evolution of heat, like the niter those formed with evolution of
analyzed by Stas and by Richards.

An entirely new light has been thrown on the numer ical relations of the atoms by the remarkable discovery of radium by the Curies, and by the discovery by Ruthfrom its salts, as well as from those of thorium, are produced by gases resembling in their inertness the gases of the argon group. These gases, moreover, have
the extraordinary property that they are transient, although they change in very different intervals of time. Whereas the gas from thorium is half gone in about a into some other substance or substances), that from radium requires about four days before it has undergone half the change of which it is capable. A third gas has been obtained from a radio-active element to which the name "actinium" has been given by its diswhich the name "actinium" has been given by its dis-
coverer, Debierne; this gas has an extraordinarily short life, for the total duration of its existence is only a few seconds. The spectrum of the gas from radium ha been mapped by Ramsay and Collie; the amount of gas produced from a known weight of radium bromide too, proved that one of its products of decomposition is the lightest gas of the argon group, helium. At first, the spectrum of the emanation from radium shows none of the characteristic lines of helium; but in the course brilliancy. Here, evidently, is a case of the transformation of one element into another; no doubt there are other prorlucts than helfum, but what they are remains iron, for example, there are at present no known means which would be produced. These gases from radium, thorium, and actinium are self-luminous, and shine of altering air and other gases with which they are mixed, so that they acquire the property of discharg. ing an electrified body; the air is said to be "ionized." But a still more remarizable property is their giving of heat during their change into other elements, the
amount of heat being enormous when their extremely small quantity is considered. Thus, the radium emanation (the name applied to the gas which is continuously evolved irom salts of radium during their existence of about 1,100 years; for, at the end of that time, the change is complete, and no more radium is left as such), during the 28 days of its decomposition, gives off no less than three million times the heat which ume of a mixture of oxygen and hydrogen in the proportion requisite to form water. Now, if radium is disacpearing, it must be continually in process of for the earth; it would all have disappeared and have been changed into other bodies in 1,100 years. As radium is always associated with uranium, it appears not unreasonable to suppose that uranium, too, which is a radio-active element, is slowly changing into radium; and there appears to be definite ground for the sur ments, also discovered by Madame Curie, which has a ments, also discovered by Madame Curie, which has a
life of little more than one year, is a product of the decomposition of radium, with which it is always assodecomposition of radium, with which it is always asso-
ciated. It may be mentioned, too, that all minerals containing uranium contain more or less helium.

It will be noticed, on referring to the periodic table, which are undergoing change of the nature described, have very high atomic weights. That of uranium is 240 ; that of thorium, 232 ; and that of radium, 225. it is not possible to build up compounds of carbon and it is not possible to build up compounds of carbon and hydrogen of unlimited complexity; indeed, it is doubt-
ful if any compound has been prepared containing more than 54 atoms of carbon. Attempts to prepare them lead to failure, owing to their decomposing at the ordinary temperature into compounds containing a smaller number of atoms. And it is probable that more complex hydrocarbons, as such compounds are termed, would, if they could exist, decompose with evolution of heat. Such a decomposition appears to present analogy with the change which an element like other elements of lower It is in process of change into ing, it evolves heat, in amount enormously greater than that produced by any change of a compound into a mixture of simpler compounds. But the matter is ing, with almost inconceivable velocity, particles which aprear, according to J. J. Thomson, to be identical
with negative electricity. These "corpuscles," as they have been termed, imbed themselves in the vessel in which the radio-active body is confined; and, owing to their extreme minuteness, they may even pass through
the walls of the containing vessel. Indeed, the opposithe walls of the containing vessel. Indeed, the opposi-
tion to their passage has been shown to depend merely on the density of the matter of which the confining on the density of the matter of which the confining
walls are composed; gold, which is denser than lead, stops their passage better than lead; for a similar reaon lead is better than iron, iron better than glass, and so on. Thomson has calculated that the mass of
one such particle is approximately one-thousandth of one such particle is approxi
that of an atom of hydrogen.

This new chemistry is just at its commencement. It
Then an atom of hydrogen. dates from 1896, when Becuerel showed that com. pounds of uranium evolved some sort of radiation,
which would impress a photographic plate. It is still too early to formulate any definite statement relating
to its connection with the irregularity in the numerto its connection with the irregularity in the numer-
ical sequence of the atomic weights; yet it may be perical sequence of the atomic weights; yet it may be per-
missible to speculate, aided by the recent liscoverios. missible to speculate, aided by the recent discoveries.
When two elements combine, heat is generally evolved; now heat is only one form of energy, and the combination of elements may be so carried out as to bc accompanied by other kinds of energy-for instance, by when a compound is resolved into its elements, it is generally necessary to impart energy to it; and the ergy than its compounds. Now, as Ostwald has pointed out in his "Faraday" lecture, the progress of diswhich it was possible at the time to load a compy with and he cited the discovery of the metals of the alkalies, sodium, and potassium, by Davy. It was because Davy had at his disposal the powerful battery of the Royal Institution, that le was able to convey enough energy into caustic potash to isolate from it potassium, hydrointo caustic potash to isolate from it potassium, hydro-
gen, and oxygen. If we assume that radium, as may be gen, and oxygen. If we assume that radium, as may be
possible, is produced by a spontaneous change in ura nium; and if we also assume that radium contain more energy than uranium; then, as such a spontane ous change must be accompanied, on the whole, by loss of energy, there must be formed other bodies from the uranilm which contain less encrgy than it doess.
Such a substance may be iron, which is generally found in company with uranium. If we could concentrate energy into iron, it might be possible to convert it into vranium.

But there is another sirle to this question. The na character. Now, it is almost certain that negative ele tricity is a particular form of matter: and positive that is, minus this electric matter. The addition of 
matter in any form would, according to all experience, increase mass; it would also increase weight. It is, therefore, conceivable that an element may consist of a compound of two or more elements of lower atomic weight, plus a certain quantity of negative electricity. This might account for the approximate numerical relations which subsist between the atomic weights of the nearly related elements; and also for the fact that the relation is not an exact one, but only approximate; for the difference between the actual atomic weight and that which would follow if one element were compound of other elements of lower atomic weights, would be caused by the addition of a certain number of electric atoms to the molecule.

It must be confessed, however, that the basis for speculations like these is a slender one; the sole ground is the undoubted fact that radium produces an emanation, which spontaneously changes into helium; and also that, in doing so, the emanation parts with a large number of corpuscles carrying negative charges. Nevertheless, enough is known to prove that there is a wide terial was free from aldehydes, then the result of the above purifying process will be a light, clear thick oil free from taste or odor-Oesterreichischer Chemiker u. Techniker.

THE MAKING OF AN INCANDESCENT MANTLE. By DAY ALLEN WILLEY

ONE of the most interesting modern industries, and ne which is notable for the number of delicate processes which attends it, is the manufacture of incandescent mantles for illumination by means of gas. IVhile the general term for these articles is Welsbach, after the famous chemist whose discoveries produced a revolution in the industry, there are several different kinds, although the refractory properties of the majority originate from a few elements. In the periments of Velsbach, which resulted so successfully, cotton fabric was saturated with a solution which contained the oxides of zirconium, lanthanum, and yttrium. The latter substances represented 20 per give the mantle the brilliancy which makes it so popular. In combining the elements, it is necessary to have a certain temperature, also what the chemist erms an exact air adjustment, otherwise the quality me seriously affected. Upon the temperature and air adjustment depend largely the percentage of ceria which is added to the thoria. From time to time other substances have been added to those mentioned, with a view of improving the quality of the light. They include silicic acid, oxide of arsenic, and antimony, but apparently have failed to raise the standard.

The fabric utilized in the modern gas mantle is principally cotton, although ramie fiber has been employed with success in Germany. Before the refract ory salts are applied to the fabric, however, it is first arefly a freed from impurities by immersing it in caral baths. In the factories turning out the highest grades of mantles, the cotton is first immersed in dilute alkali, then in dilute acid, and finally washed thoroughly with distilled water, for it is necessary to remove every particle of foreign matter if it is to be
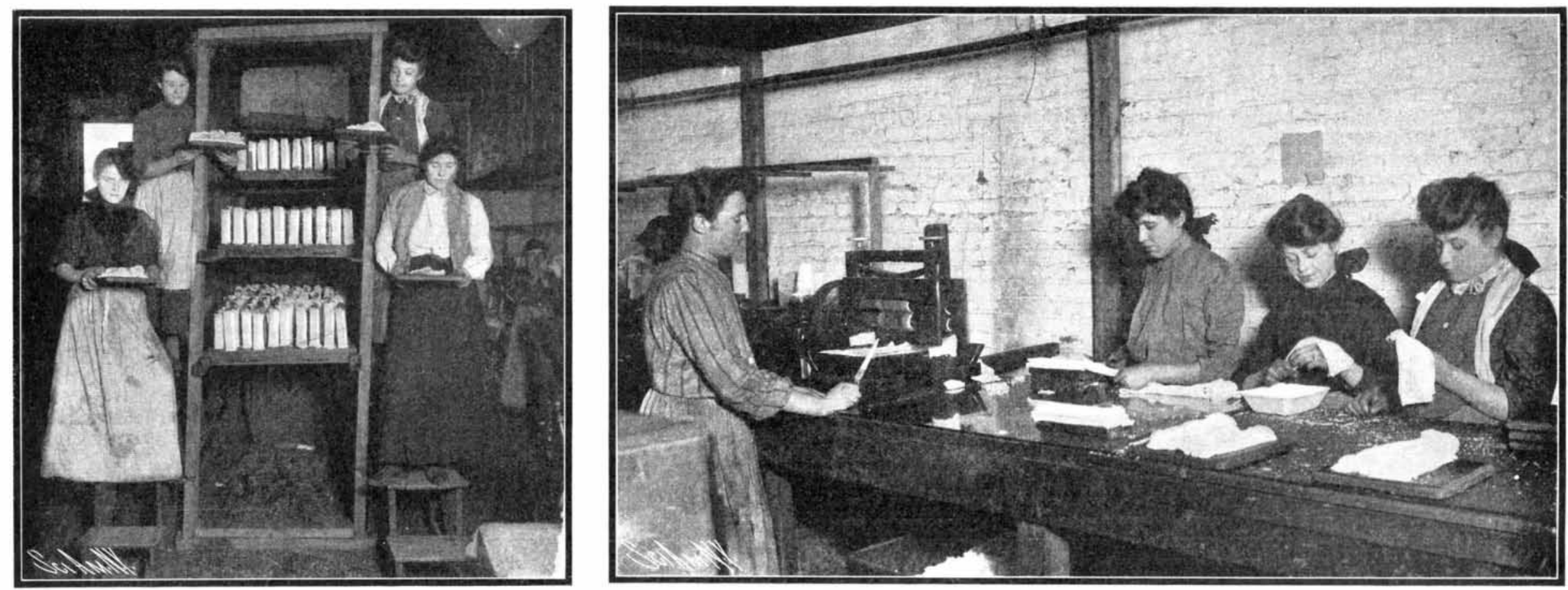

DRIING MANTLLS AF'TER BEING SHRUNK ON THE MODELS.

CUTTING THE MANTLES INTO THE PROPER ILENGTHS BEFORE SHRINKING THE FABRIC.

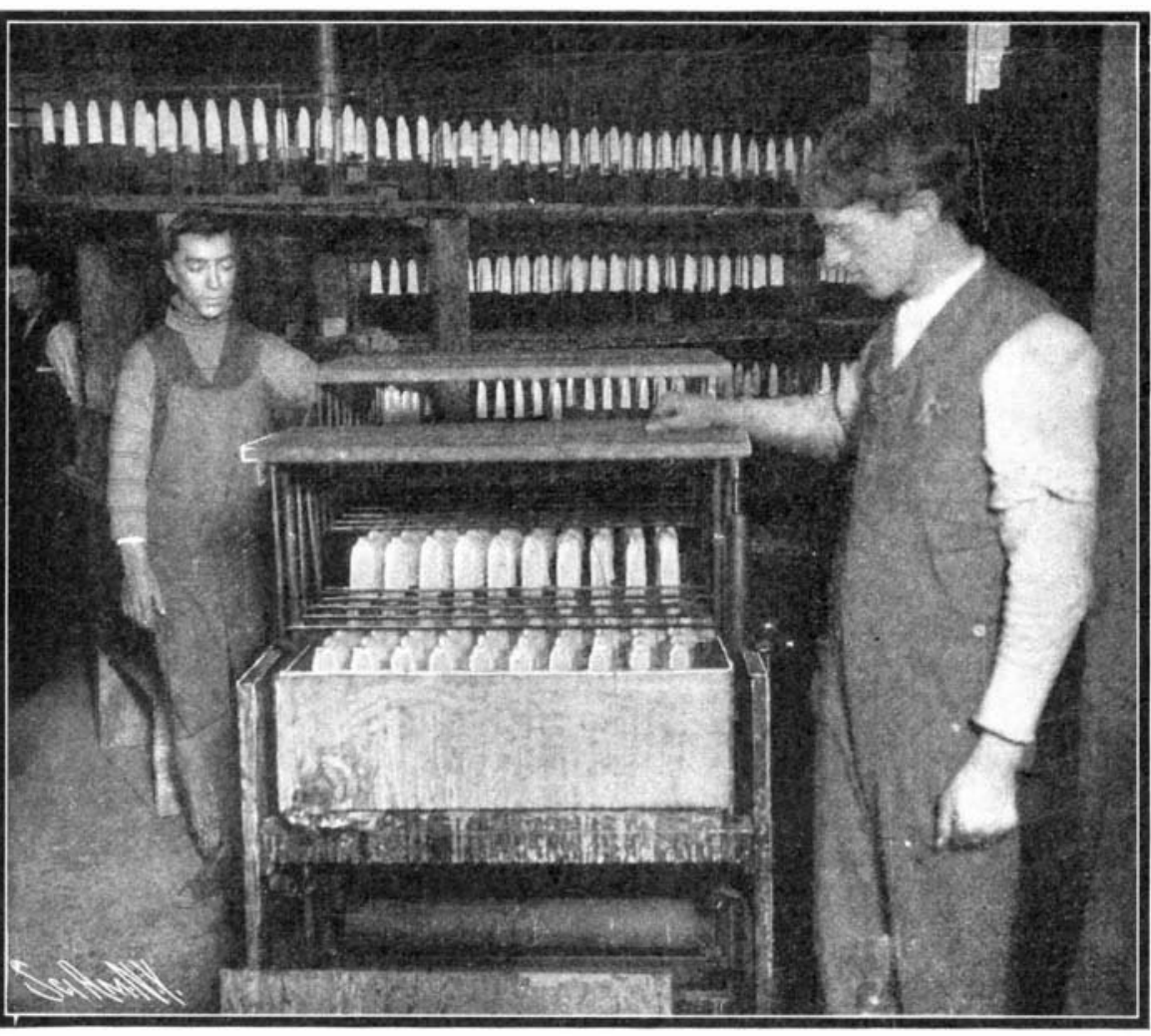

APPARATUS FOR IMMERSING MANTLES IN THF HFA'T-R HOS'TING COA'TIMG

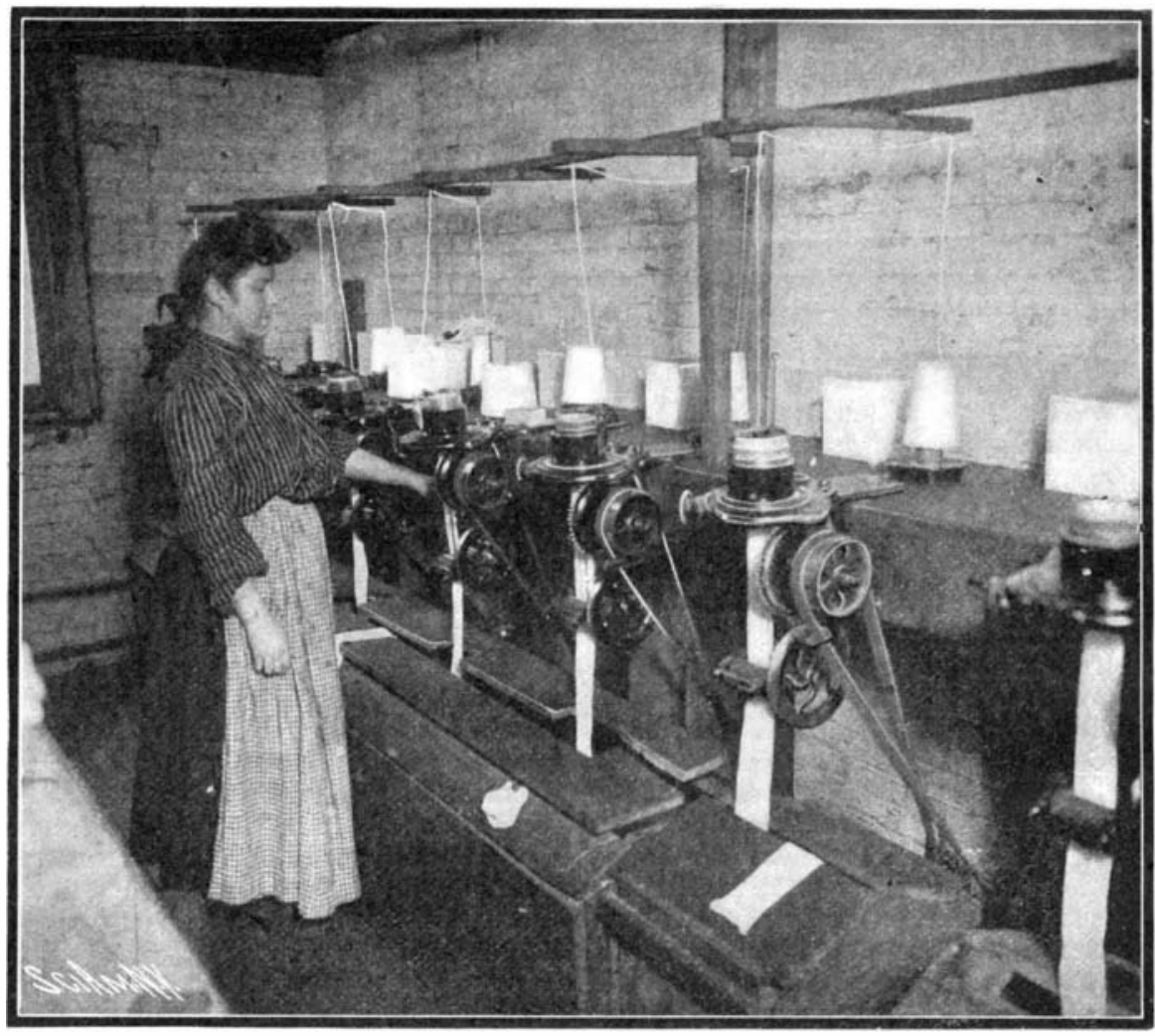

FORMING THE FABRIC FOR THE MANTLES. SOLUTION

THE MAKING OF AN INCANDESCENT MANTLE.

field for experiment, and that the harvest will be a rich one; further, the reapers' task will be one of extraordinary interest.

Purifying Castor Oil.-Deacidify the crude oil with alcoholic alkalies, remove the soap thus formed first with dilute methyl alcohol, ethyl alcohol, or acetone, and after that in the well-known manner with water. For instance: Take 100 kilogrammes of castor oil which may have the acid value 12 , and agitate it con tinuously for a time in a solution of 2 kilogrammes of ammonia soda dissolved in 100 kilogrammes of 50 per cent alcohol. When this fluid is left to itself, in a short time it separates into two layers, an upper stratum of oil and an under stratum consisting of an aqueous alcohol solution of soda and soap. After being drawn off the stratum of oil is now washed with which of wine which has ben wathe or 50 deg. C. until an emulsion. Now shake it up vigorously with warm water several times, and dry it. If the original ma- cent each, and the former 60 per cent of the compound. Later it was discovered that cerium formed an excellent substitute for lanthanum, the element being obtained in cerite earth.

As the experiments progressed, Welsbach utilize thoria as a substitute for zirconia, and in utilizing it discovered its great value as a basis in mantle construction. In later processes thoria combined with ceria was found to produce the most brilliant and at the same time the most durable illumination, where the elements were combined under proper conditions, and to-day the best grades of mantles are composed of these elements, as well as alumina treated with chromic acid. Thoria in itself has practically no illuminating properties, although it is an interesting fact that in the present manufacture of mantles, as carried on in this country, from 97 to 99 per cent of it is used in connection with ceria, the proportion of the latter element ranging from nine-tenths to threo per cent, but even this small amount is sufficient to

* Specially prepared for the ScIEnTIFIC American SUPPLEmENT. perfect. The thoria and ceria are combined in a sotion the mantles are dipped, suspended from racks, each rack being gradually immersed by hand until ed. After removal hey are dried by being exposed to currents of warm air, after which a solution containing collodion may be added before firing or after the mantle has been reduced to a skeleton composed of oxides in the retort.

The fact that the fabric with its chemical coating must be "burned off" is one reason why so few of the elements available for making it incandescent can be employed. Some of the salts which might be available shrink it, when heat is applied, to such an extent that a mantle of very large size is required to obtain the oxide shell of the proper proportions. Other salts The disappears, and the mantle becomes worthle the principal advantage of thoria illu, aside from the fact that it gives forth such an 